\title{
PHOENIX-LANCE STEELMAKING
}

Here is an interesting new steelmaking technique being developed in Germany for the production of open-hearth quality steels from highphosphorus pig irons. It utilizes the classical basic-bessemer converter with top-blown oxygen, and has the advantages of early phosphorus removal and, consequently, less nitrogen pick-up in the final steel.

\author{
by $\mathrm{H}$. Th Brandi
}

A $t$ the Ruhrort plant of Phoenix-Rheinrohr AG in Germany, tests have led to the development of a new steelmaking process. This is the PhoenixLance, or the PL process, which is now ready for industrial application.

The new process, for which a patent application has already been filed, is conducted in the usual, basic-bessemer converter. The converter is not only bottom-blown in the upright position, but the blow is continued for a period with the converter tilted on its side, thus obtaining metal-slag reactions of the same kind as those occurring in the openhearth furnace.

\section{Operation of PL process}

The operation of the PL process will be clear from the accompanying reaction curves for a blow, Fig. 1. In the first stage of the process, basicbessemer pig is refined by bottom-blowing to a carbon content between 0.4 pct and about 0.1 pct. Then, for the second stage, the converter is tilted on its side, to act for a time as a kind of openhearth furnace.

A water-cooled oxygen lance is now introduced into the mouth of the converter. By blowing plant oxygen, or pure oxygen, on the melt, the slagformers are quickly melted down, obtaining, in addition to a slight degree of decarburization, a steady slagging-off of the phosphorus.

Finally, a brief raising of the converter and blowing with blast air and/or oxygen-boosted blast, lowers the phosphorus percentage within a few seconds to values of the order of 0.020 to 0.040 pct. It is generally possible simultaneously to control the carbon content of the steel bath within 0.02 to 0.10 pct, or higher values, if required. Naturally, by applying a secondary slag, the phosphorus content of the steel can be fairly easily brought down in essentially the usual manner to quite low levels. The final slag, i.e., the slag after the third process stage, corresponds to an ordinary basic slag, and can be credited with its full value as a fertilizer.

Since the PL process enables the dephosphorizing to be conducted in practically the same manner as in an open-hearth furnace, and the carbon percentages at the end of the actual refining blow are of the same order of magnitude as in the openhearth process, the problems of nitrogen and oxygen elimination are practically solved. The nitrogen figures for PL steel are between 0.003 and 0.005 pct, while the oxygen percentages follow the carbon content of the refined, finished steel, as in the open-hearth or the LD process. Desulfurization

H. Th. BRANDI is with Phoenix-Rheinrohr AG, Düsseldorf, Germany. This article originally appeared in StahJ und Eisen, June 26, 1958, and a translation was later published in the Iron and Coal Trades Review.
Fig. 1-Reaction curves for a blow using the Phoenix-Lance process.

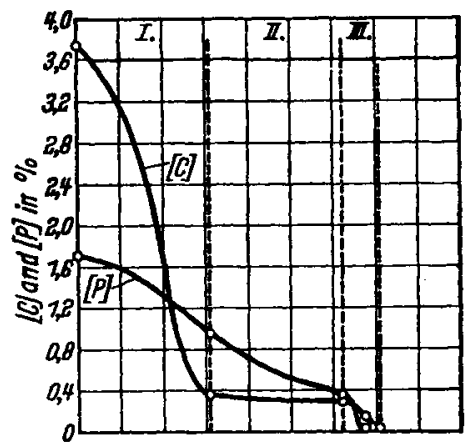

is 70 to 80 pct, equaling that obtained in the buffer slag tests by Kosmider; Schenck, and others; the resulting advantages are obvious. Five PL heats had the following average analyses: 0.114 pct $\mathrm{C}$, 0.298 pet $\mathrm{Mn}, 0.028$ pet $\mathrm{P}, 0.014$ pet $\mathrm{S}$, and 0.004 pet N.

Total blowing time is about $15 \mathrm{~min}$, or little longer than in the ordinary, basic-bessemer process. Oxygen consumption is about $2500 \mathrm{cu} \mathrm{ft}$, of which over 50 pct is provided by atmospheric oxygen.

\section{Importance of PL process}

As already mentioned, the importance of the basic-bessemer process for Western Europe remains demonstrable, since there are still available supplies of high-phosphorus ores sufficient for many years.

The fact that the corresponding open-hearth steels with low copper and tin contents have to be made from pig-irons-hence from ores-particularly low in such undesirable metallic contaminationsis a considerable advantage of the present process.

From the point of view of the steelworks operator, the PL process affords substantial operating advantages. During a campaign, the blowing characteristics of a converter tend to change considerably. Furthermore, in a bessemer plant above all others, much depends on maintaining a suitable working rhythm, this applying equally to the sequence of heats, and to the relining of the converters and bottom replacements. It is immediately obvious that retaining the classical bessemer converter and using it for the production of steels equal to open-hearth quality, brings with it the considerable advantages of the fast-working rhythm and operational readiness of the converter plant.

These considerations have impelled PhoenixRheinrohr AG to contemplate the construction of an entirely new basic-bessemer steelworks of the classical type.

(At the Ruhrort plant of this firm, plans have been formulated for the construction of a new plant for the production of $6000 \mathrm{cu}$ per hr of 99.5 pct 